\title{
Differing semantic elements as agents of change in Malay - English translation
}

\author{
Kais Amir Kadhim \\ Faculty of Language and Linguistics, English Department, University of Malaya
}

Email address:

Kaisamir2009@yahoo.com (K. Amir Kadhim)

To cite this article:

Kais Amir Kadhim. Differing Semantic Elements as Agents of Change in Malay -English Translation, International Journal of Language and Linguistics. Vol. 1, No. 1, 2013, pp. 7-15.doi: 10.11648/j.ijl1.20130101.12

\begin{abstract}
The aim of this paper is to investigate the translation of Bahasa Malaysia headlines into English semantically. The objectives of this study are : (i) to identify the procedure / strategies used in the translation of BM headlines into English. (ii) to find out if the message of the Source Language (SL) is retained in the Target Language (TL).Towards that end, a componential methodology of the ST and TT will be adopted by paying attention to examine the differences and similarities of the content of the messages in the ST and their corresponding messages in the TT. In the evaluation of the messages of the texts (both ST and TT), Newmark's(1981) approaches in translation shall be used, in particular the employment of his terminologies such as overtranslation, undertranslation, and ambiguous translation. In addition, our observation of any difference in the messages of the ST and the TT (both the linguistic meaning and the extra linguistic meaning) shall be stated using the semantic notation of the componential analysis of Katz and Fodor (1963) and as extended in Jackson (1988). In some places in addition to the notation, a simple supplemental narration shall be employed especially in dealing with cultural messages and other nuances in the realm of pragmatics. It is found that the message have merely been diffused, or being put in a time frame (tenses) to suit the culture, political make up, the Malay grammar and sociolinguistic idiosyncracies of Malay target reader.
\end{abstract}

Keywords: Translation, Message, News, Linguistic And Culture

\section{Methodology}

\subsection{Newmark'S Ideas in Newmark $(1981,1988)$}

As Newmark (1981: 7-8) rightly points out, the translator is a victim of a constant tension between the acts of overtranslation and undertranslation. He contends that a lot of semantic gaps in translated texts arise because of this tension. To him, overtranslation is a translation that gives more detail and a more specific word than its corresponding during the translation procedures (Newmark, 1988:284). And undertranslation gives less detail and is more general than the original (Newmark, 1988: 285). In addition to semantic and communicative translations approaches, ambiguous translation to Newmark (1981:122) “...carry a deal of lexical and grammatical ambiguity, which may be linguistic or referential; hopefully all this ambiguity will be cleared up by the micro-and macrocontext. Where the ambiguity remains in spite of the macrocontext, the translator has to determine whether it is referential or linguistic, or between the two extremes," (Newmark: 1981:122).

\subsection{Componential Analysis by Katz and Fodor (1963)}

Denotive words and their meaning can be differentiated using the methods of componential analysis as first propounded by Katz and Fodor (1963). Componential analysis refers to a semantic analysis in which meanings of lexemes are analysed into components, and which can be compared across lexemes or groups of lexemes (Jackson, 1988:79). Components have distinguishing functions that are used to distinguish features of lexemes within a specified semantic domain (Jackson, 1988:81).

There are two general types of semantic component, namely common component and diagnostic component (Jackson, 1988: 83). A common component serves to identify a semantic domain, where the distinguished component is shared by all the lexemes in the domain. The second type is diagnostic. Katz and Fodor exemplified this contention with the word bachelor which is (a) human, (b) male, and (c) unmarried. Such information with respect to the word bachelor can be expressed by providing a list of three binary components: [+ human], [ + male], and [- married] 
where the plus symbol $[+]$ denotes the presence of an information while the minus symbol [-] indicates the absence of such information. In the case of hydra which is biologically both male and female, it carries the information [ + male and - male] in which its unique characteristic can be stated as $[+$ male $]$.

\section{Data Analysis}

\subsection{Replacement Translation}

The tables below illustrate examples of Replacement Translation. Replacement Translation, in this case, refers to total change in the meaning of a word or phrase of the SL.

Table 1 illustrates a comparison between the SL word 'mahu' and TL term 'says'. From the data above, it was found that there is no difference between the style of SL and TL in which both words serve as the main verb in their respective sentence. However, the SL and TL terms differ greatly in meaning. The SL word 'mahu' carries the denotation of 'want' and 'need' but does not carry any meaning of 'report' as stated in its semantic features [+want, + need, - report]. When this term was translated into English, there is a complete change in meaning where the TL word 'says' carries the meaning of 'report' but does not carry any meaning of 'want' or 'need' ([+report, -want, -need]). There is a total loss of semantic features of the SL text (i.e. [-need, - want]) but the term is replaced with a new term which also consequently provides a new set of semantic features ([i.e. [+report]) to the TL version. This total change in meaning of both SL and TL text thus, shows that Replacement Translation has taken place. There is a change in the meaning from 'mahu' to 'says'. There is a total loss of the SL meaning simultaneously, there are additions of new features in the TL word. For example, the word 'says' carries the feature of [+report, - want]. From this, it can be said that 'says' carries a more neutral tone to the message but 'mahu' which carries the feature of [+want], brought a sense of 'demand' or 'instruct'. Therefore, the meaning of the SL word has been neutralised. The possible explanation of this occurrence is the translator prefers to be objective in his or her translation. This is further supported by the structure of the headlines in which, the SL is a declarative sentence whereas the TL version is more of an imperative in reported speech. Therefore, in SL headline, the main focus is on MCA and the action that is being taken by MCA. However, in TL, MCA is being back grounded and the main focus is on the action of 'release'. In SL, the word 'segera' which denotes 'immediate' in Bahasa Malaysia indicates the sense of urgency of the action taken by MCA and that the issue is being taken seriously by this particular party. However, this voice of urgency is loss after translation because there is no equivalent word that refers to the word 'segera' in the TL. Overall, there is a loss in the meaning when being translated to TL. It can also be concluded that the overall message is being neutralised in the TL as compared to SL headlines.

\section{Data 1}

Table 1. Headline (MCA mahuk'jaansegeralepaskan Al-Kitab.)

\begin{tabular}{ll}
\hline SL & MCA mahuk'jaansegeralepaskan Al-Kitab. \\
\hline TL & Release Malay Bibles, says MCA \\
BT & BebaskanInjilBahasaMelayu, kata MCA \\
$\begin{array}{l}\text { Style of SL } \\
\text { and TL }\end{array}$ & $\begin{array}{l}\text { SL: mahu [V] } \\
\text { TL: says [V] }\end{array}$ \\
$\begin{array}{l}\text { Semantic } \\
\text { features of SL } \\
\text { and TL }\end{array}$ & $\begin{array}{l}\text { SL: mahu [+V, +want, +need, -report] } \\
\text { TL: says [+V, +report, - want, -need] }\end{array}$ \\
& $\begin{array}{l}\text { There is no difference in style but SL and TL differs } \\
\text { greatly in semantic features. The SL 'mahu' carries the }\end{array}$ \\
$\begin{array}{l}\text { Effect on } \\
\text { message }\end{array}$ & $\begin{array}{l}\text { meaning of 'want' whereas the TL 'says' carries the } \\
\text { from SL to TL, this translation of the text is hence, a }\end{array}$ \\
& Replacement Translation. \\
\hline
\end{tabular}

The data in Table 2 shows no difference in the style of SL 'cetusbantahan' and TL 'causes outrage'. Both phrases are verb phrases with the structure of [V-N]. Similar to the data in Table 1, there is a complete change in the meaning of SL after translation. The SL phrase 'cetusbantahan' literally means 'evoke protest' but this meaning is changed to the TL version of 'causes outrage' after translation. As can be seen in the semantic features of both phrases, the meaning of the SL focuses more on the action of protest and objection [+protest, +objection] whereas the TL emphasizes on the emotion rather than the action [+anger, protest, - objection]. Due to this total change in the meaning of SL after translation, it is hence, a Replacement Translation. Headline 2 indicates that there is a change in meaning from 'cetus' to 'causes'. 'Cetus' carries the features of [+erupt, + evoke] whereas 'causes' carries the features of $[+$ create, + induce, -erupt, - evoke]. Here, 'causes' gives an impression of something is being created intentionally while 'cetus' is an abrupt outburst.

There is also a change in meaning from 'bantahan' to 'outrage'. There is a total loss of SL meaning whereby 'bantahan' carries the feature of [+protest, + objection] however 'outrage' carries the feature of [-protest, objection]. 'Outrage' carries the additional feature of [+anger, +fury]. This indicates that SL emphasises on physical action while TL emphasises on emotion. The TL gives a more passive kind of reaction towards the issue as compared to SL. In order to retain the similar impact of the SL headline, the translator could have used a more equivalent phrase for 'cetusbantahan' such as 'evokes objection / protest / demonstration'. By using 'outrage', there is a meaning change in the message. This could be due to the fact that the translator would like to focus on the emotions of the protestor instead of the action done by the protestor. Overall, there is meaning loss in TL message when being translated from SL. 
Data 2

Table 2. Headline (Kartun tsunami BeritaMingguancetusbantahan)

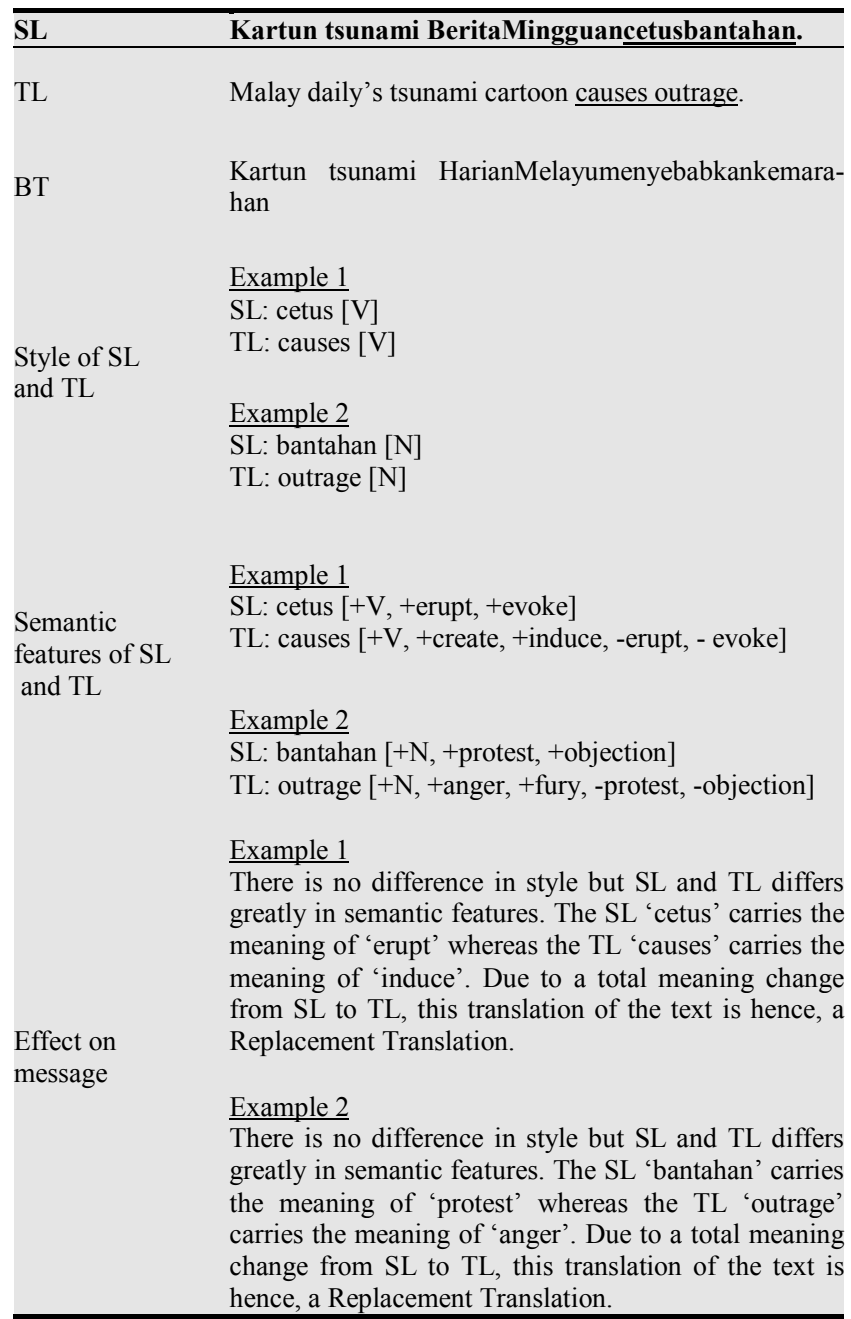

Data 3

Table 3. Headline (Amaranuntuksiswasertaijamuankek anti-menara)

\begin{tabular}{ll} 
SL & Amaran untuksiswasertaijamuankek anti-menara \\
\hline TL & UTAR warns students over anti-tower cake party \\
BT & $\begin{array}{l}\text { UTAR memberi amaran kepadapelajarmengenaijamuankek } \\
\text { anti-menara }\end{array}$ \\
$\begin{array}{l}\text { Style of } \\
\text { SL and TL }\end{array}$ & $\begin{array}{l}\text { SL: sertai [V] } \\
\text { TL: over [P] }\end{array}$ \\
$\begin{array}{l}\text { Semantic } \\
\text { features } \\
\text { of SL } \\
\text { and TL }\end{array}$ & $\begin{array}{l}\text { SL: sertai [+V, -P, +join, +participate, + take part] } \\
\text { TL: over [+P, -V, +on, -join, - participate] }\end{array}$ \\
$\begin{array}{l}\text { Effect } \\
\text { on } \\
\text { message }\end{array}$ & $\begin{array}{l}\text { The SL and TL headlines differ both in style and semantic } \\
\text { features. SL term 'sertai' is a verb carrying the meaning of } \\
\text { preposition which links the structure of the headline. The TL } \\
\text { text carries the meaning of 'on' which does not exhibit any } \\
\text { denotation of an action as shown in the SL text. Due to a total } \\
\text { meaning change from SL to TL, this translation of the text is } \\
\text { hence, a Replacement Translation. }\end{array}$ \\
\hline
\end{tabular}

A comparison between SL and TL reveals great differences in the style and semantic features of both SL and TL texts. The SL term 'sertai' acts as the main verb of the structure in which it denotes the action of 'join' and 'participate' $[+\mathrm{V},+$ join, +participate $]$. On the contrary, the TL word 'over' is a preposition which does not indicate any action of participation [-V, -join, -participate] as portrayed by the SL text. It merely serves as a link in the structure of the headline which carries the meaning of 'on' [+on]. Due to this total change of meaning from the SL text into the TL version, this type of translation is thus, a Replacement Translation.

In headline 3 , there is an addition of meaning In the TL headline. The SL word 'angka' refers to a neutral word. It carries the feature of [number, +figure, +digit, -loss, - casualties]. On the other hand, the TL word 'toll' carries the features of [+casualties, +loss]. 'Toll' adds sombre and serious mood as compared to the SL headline. Possible reason for this would be that the translators might want to highlight the severity of the incident which is a strategy to draw attention to the news by arousing readers' sympathy. This serious mood is further emphasized by the use of 'top' which is normally used to indicate the 'highest point'. This amplifies the effect on the message. The SL 'lebih' refers to an action of 'increase'. It also carries the features of [+over, +more than, + increase] while 'top' carries the features of [+exceed, + outrun, + surpass]. The SL word refers to the action of increasing but the TL is more to letting the reader know that the death might exceed the highest peak. The translator may have used the word 'top' as in to emphasize on the extreme increase in the number of casualty. Basically the overall message is retained. In fact, morphologically, syntactically and semantically, both headlines are very similar. The only conspicuous difference is that the TL headline employs more emotionally-attached words such as 'toll' and 'top' which magnifies the effect of the TL headline on the readers.

\subsection{Undertranslation}

In this section, we will present 3 cases of undertranslation. They are presented in tables 4,5 , and 6 .

The table above indicates that 'SMK' and 'school' undergoes the process of under translation. There is no difference in the style of SL and TL where both are nouns. On the contrary, there is difference in the semantic feature for both words. The SL word 'SMK' carries the semantic features of $[+$ specific school, + secondary school, + national school, - primary school, - private school] while 'school' carries the semantic feature of [- specific school, + secondary school, + national school, + primary school, + private school]. 'SMK' is the acronym for 'SekolahMenengahKebangsaan' which means national secondary school in Bahasa Malaysia and is specific to learning institutions that consist of students who are learning from Form One to Form Five or Form Six. However, 'school' is a general term for a learning institution that does not refer to any 
specific type of school. It may consist of primary school, secondary school or even pre-school. In headline 4 , it is clear that in the SL use of 'SMK' signifies a specific type of school however the TL uses a more general term which is 'school' which signifies any types of school. This leads to the TL undergoing the process of under translation. But based on the componential analysis of the word 'school', the semantic features that this word carries do not adequately reflect the loss of information. In fact, the word 'school' carries more features such as $[+$ secondary school, + national school, + primary school, + private school]. However, the finding for the headline above indicates the opposite where there are more features carried by the TL 'school' thus signifying more contextual meaning. A possible reason for this is because the translator does not want to emphasise on the type of school that is involved. Similarly, the word 'novel' is generalised in the TL by the use of the word 'book'. The TL term does not indicate the specific type of book as portrayed by the SL 'novel'. A 'book' may carry the feature of an atlas or a magazine or any religious reading material, whereas a 'novel' does not carry these features. The choice of words indicates that the translator is playing with words in the TL headline. The phrase 'book closed' can mean either the closing of a book which is an action normally done when a reader finishes reading or it can mean 'issue / matter' is settled. In this case the headline means the latter to highlight the end of the issue. Overall, the message of TL headline is being under translated.

Data 4

Table 4. Headline (Isu novel Interlok di SMK KKB selesai)

\begin{tabular}{ll}
\hline SL & Isu novel Interlok di $\underline{\text { SMK KKB selesai }}$ \\
\hline TL & Book closed on KKB schoolInterlok issue \\
BT & PenutupanbukuisuInterlok di sekolah KKB \\
& \\
$\begin{array}{ll}\text { Style } \\
\text { of SL } \\
\text { and TL }\end{array}$ & SL : SMK : school $[\mathrm{N}]$
\end{tabular}

Semantic SL : SMK $[+\mathrm{N},+$ specific school, + secondary school, features + national school, - primary school, - private school] of SL TL : school $[+\mathrm{N},-$ specific school, + secondary school, and TL + national school, + primary school, + private school]

There is no difference between the style of SL and TL text but Effect both differs in semantic features. The SL 'SMK' does refer to on any specific types of school. However 'school' does not refers message to any specific school. Therefore, the SL text undergoes Under Translation process.

\section{Data 5}

Table 5. Headline (Amaranuntuksiswasertaijamuankek anti-menara)

SL SL

$\mathrm{TL}$ Amaran untuksiswasertaijamuankek anti-menara

BT

UTAR memberi amaran kepadapelajarmengenaijamuankek anti-menara

Style of SL and TL

SL: siswa $[\mathrm{N}]$

TL: students $[\mathrm{N}]$

Semantic

features

of SL and TL

SL: siswa $[+\mathrm{N},+$ students, + graduate, - primary school students, - secondary school students] TL: students $[+\mathrm{N},+$ learners, + graduates, + pupils, + primary school students, + secondary school students]

Effect on message

There is no difference between the style of SL and TL text but both differs in semantic features. The SL 'siswa' refer to specific group of learners. However 'students' refers to more general group of learners. Therefore, there is Under Translation that takes place.

The table above indicates that the word 'siswa' and 'student' undergo the process of under translation. There is no difference in the style of SL and TL. Both are nouns. On the other hand, there are differences in the semantic features where 'siswa' have the features of $[+$ students, + graduate, - primary school students, - secondary school students] while 'students' have the features of [+ learners, + graduates, + pupils, + primary school students, + secondary school students]. 'Siswa' holds the feature of a student who is studying in a university or college while 'students' is a general term for someone who is learning in an institution regardless of the level. Thus, it can be seen that 'students' carry more meaning as it can be applied to various stages of educational level.In headline 5, the structure and the meaning are basically the same, except for the word 'soal'(SL) and 'stand' (TL). Both 'soal' and 'stand' have a total different semantics feature. 'Soal' carries the features of [+matter, + issue, +concern, + problem] whereas 'stand' carries the meaning of [+opinion, + view, + stance]. Since the meaning of 'soal' and 'stand' are totally different. Thus both the words are not in the same platform to be compared in the sense of 'lesser' or 'more' meaning or features. Due to the completely different meaning as illustrated by TL 'stand', it is obvious that there is a loss of the original meaning as indicated in SL 'soal' although a new set of features is introduced after the translation. It is clear that there is an addition of meaning. Possible reason for this is that the translator wants to emphasize on the opinion rather 
than on the problem of stamp and serialization. Overall, there is a change of meaning after the process of translation. The original meaning of the SL headline is not retained. There is a slight effect in the whole message that is conveyed in both SL and TL. The SL headline tends to focus on the problem that arises regarding the stamp and serialization whereas the TL is focusing more on the stance or view of the government regarding the particular issue.

Table 6 shows no difference in the style of the SL text 'korban' and TL text 'victim' where both terms function as nouns in their respective headline. However, there is a slight change in meaning. Although both terms refer to the people who are affected by the earthquake, the TL term 'victims' are more general and carries less meaning. As illustrated in the Componential Analysis in Table 10, the TL term 'victim' has the same semantic features as the SL term 'korban' i.e. [+ victims, + death, + injured, + sacrifice] except that it does not carry the feature of 'sacrifice' [sacrifice]. Due to the fact that there is less meaning in the TL text, this is thus, an Under Translation.In headline 10, the word 'korban' in SL is translated into 'victims' in the TL. SL 'korban' carries the features of [+ victims, + death, + injured, + sacrifice $]$ while 'victims' carries the features of [+dead, + injured, - sacrifice, + loss]. 'Korban' signifies specifically to those who are 'dead' but 'victims' can refer to those who are still dead or alive. Here it can be clearly seen that the effect of the word 'korban' is reduced after the translation. It can be said that the translator attempts to reduce the severity of the issue by using a more general statement. Apart from that, there is also addition in the meaning of the TL headline. This is because of the use of the word 'increase' to substitute the word 'lebih' in the SL headline. The word 'lebih' provides specific detail because it is followed by the number of deaths as shown in the SL headline. On the other hand, in the TL headline, the amount is not specified and it is only mentioned generally that there is an increase in the number of victims. Therefore the impact portrayed by the figure 10,000 reduced is hence reduced. Although there is loss of information, there is also addition of information in the TL headline. For example, the addition of the phrase 'Japan's quake' is to inform the readers that 'an increase in the number of victims' is actually referring to the recent Japan's earthquake which is of main concern to the society. On the contrary, the SL headline does not indicate the 'amount of deaths' is referring to which incident. The possible reason would be because the translator wanted to catch the attention of readers since this incident has become an issue of concern worldwide. Thus, it seems that the translator is using a strategy different from the author of the SL news to catch the attention of the readers. The change in structure and lexical choice as part of the strategy leads to semantic change. The gist of the SL headline is retained but otherwise, the loss and addition of meaning in the TL headline have brought about quite an explicit change in the meaning of the whole SL text.
Data 6

Table 6. Headline (Korbanmungkinlebih 10,000)

\begin{tabular}{|c|c|}
\hline SL & $\underline{\text { Korbanmungkinlebih } \mathbf{1 0 , 0 0 0}}$ \\
\hline TL & Japan's quake victims increases \\
\hline BT & MangsagempabumiJepunmeningkat \\
\hline $\begin{array}{l}\text { Style of SL } \\
\text { and TL }\end{array}$ & $\begin{array}{l}\text { SL: Korban }[\mathrm{N}] \\
\text { TL: victims }[\mathrm{N}]\end{array}$ \\
\hline $\begin{array}{l}\text { Semantic } \\
\text { features of } \\
\text { SL and TL }\end{array}$ & $\begin{array}{l}\text { SL: korban }[+\mathrm{N},+ \text { victims, }+ \text { death, }+ \text { injured, }+ \\
\text { sacrifice }] \\
\text { TL: victims }[+\mathrm{N},+ \text { dead, }+ \text { injured, - sacrifice, }+ \text { loss }]\end{array}$ \\
\hline $\begin{array}{l}\text { Effect on } \\
\text { message }\end{array}$ & $\begin{array}{l}\text { There is difference between the style and semantic } \\
\text { features of SL and TL text. The SL 'korban' can only } \\
\text { be applicable to victims who are not alive. However } \\
\text { 'Japan's quake victims' refers to more specific group } \\
\text { of people who may be affected by the natural disaster } \\
\text { in Japan. Therefore, there is a process of Under Trans- } \\
\text { lation. }\end{array}$ \\
\hline
\end{tabular}

\subsection{Overtranslation}

In this section, we will present 3 cases of undertranslation. They are presented in tables $7,8,9$

Table 7. Headline (ISA pada yang persenda azan di Youtube)

\begin{tabular}{ll}
\hline SL & ISA pada yang persendaazan di Youtube \\
TL & Group calls for ISA over "mockery" of Azan \\
& $\begin{array}{l}\text { Kumpulandipanggiluntuk ISA atas } \\
\text { "ejekan" tentangAzan }\end{array}$ \\
BT & $\begin{array}{l}\text { SL: Persenda [V] } \\
\text { TL: Mockery [V] } \\
\text { and TL }\end{array}$ \\
$\begin{array}{l}\text { Semantic } \\
\text { features of SL } \\
\text { and TL }\end{array}$ & $\begin{array}{l}\text { TL: mockenda [+V, }+ \text { mockery, }+ \text { tease, - sarcastic] } \\
\text { contempt] }\end{array}$ \\
& $\begin{array}{l}\text { There is no difference between the style of SL and TL } \\
\text { text. But there is a slight difference in the semantic } \\
\text { features of SL and TL text. The SL 'persenda' does } \\
\text { not have the sarcastic tone whereas 'mockery' refers to } \\
\text { something which is said in a sarcastic tone and is } \\
\text { meant to insult. Therefore, there is a process of Over } \\
\text { Translation. }\end{array}$ \\
$\begin{array}{l}\text { Effect on } \\
\text { message }\end{array}$ & \\
\hline
\end{tabular}

The table above shows that 'mockery' and 'persenda' undergoes the process of over translation. There is no dif- 
ference in the style for in the SL text and TL text. Both the words used are in the form of verb [V]. On the other hand, there are differences in the semantic features where 'persenda' carries the features of [+ mockery, + tease, - sarcastic] and 'mockery' carries the features of [+ sarcastic, + tease, +insult, + contempt]. Even though the word 'persen$\mathrm{da}$ ' and 'mockery' may sound almost similar in translation, the word 'persenda' does not hold the sarcastic tone that 'mockery' has. 'Mockery' is used in a more sarcastic way; it is used in a way that it sounds more of an insult. Therefore, the message in the SL text is given a more negative tone when it is translated into the TL text.

In headline 7 , both the SL and TL words carry similar features but the SL word does not carry the tone of sarcasm as the TL word. 'Persenda' carries the features of [+ mockery, + tease, - sarcastic] whereas 'mockery' carries the features of $[+$ sarcastic, + tease, + insult, + contempt $]$. The tone of sarcasm is further emphasized by the use of inverted commas ("mockery"). The TL headline illustrates how sarcastically the translator has viewed the issue. Contradictory to the addition of the meaning in the TL headline [+sarcastic], there is also information loss in TL after the translation. The phrase 'in Youtube' is dropped in the TL headline. Possible reason for the drop of the phrase above might be because the translator wanted to emphasize more on the issue rather than where the issue has taken place. It was also discovered that there is confusion in the meaning of the TL headline 'Group calls'. This is because the phrase 'Group calls' carries dual interpretation. The original meaning of this phrase in SL refers to as 'yang'. Here it is clearly stated that the 'yang' refers to the particular individual or group who is facing the implementation of ISA. However, since there is a dual interpretation for the phrase I TL, it is unclear to which the headline refers to. "Group calls" can be either interpreted as 'a specific group who is asked to face the implementation of ISA' or 'a specific group is asking for the implementation of ISA'. In another word, the TL 'group' can function as an agent (someone that initialize an action) or a patient (the group who is requested).Overall, the TL headline is ambiguous. The intended meaning of the translator is hidden or unclear. Therefore it can be said that the message is not clearly conveyed.

The data in Table 8 indicates that there is no difference in the style of SL text 'angka' and TL text 'toll' where both terms act as nouns. The word 'angka' carries the semantic feature of [+number, +figure, +digit, -loss, - casualties] while the TL word 'toll' carries the semantic features of [+casualties, +loss]. In a semantic sense, both terms can be used to indicate 'amount' or 'number' [+number, +digit]. However, there is a slight difference in the meaning of SL and TL term. Although both words carry similar meanings, the TL text 'toll' carries an additional meaning of 'casualties' or 'loss' [+casualties, +loss] which is absent in the SL text 'angka' [-casualties, -loss]. Due to an addition of contextual meaning, this is thus, an Over Translation.

\section{Data 8}

Table 8. Headline (Angkakematianmungkinlebih 10,000, kata polis)

SL Angkakematianmungkinlebih 10,000, kata polis

TL Death toll might top 10,000 , says police.

BT Angkakematianmungkinmeningkat 10,000, kata polis

$\begin{array}{ll}\begin{array}{l}\text { Style of SL } \\ \text { and TL }\end{array} & \text { TL: angka }[\mathrm{N}] \\ & \text { Toll }[\mathrm{N}]\end{array}$

Semantic features of SL and TL SL: angka $[+\mathrm{N},+$ number, +figure, +digit, -loss, casualties] TL: toll $[+\mathrm{N},+$ casualties, +loss]

There is no difference between the style of SL and TL text but both differ greatly in semantic features. The SL 'angka' denotes 'number' and 'figure' whereas the TL 'toll' carries the denotation of 'casualties' and 'loss'. Due to a total meaning change from SL to TL, this translation of the text is hence, an Over Translation.

In headline 3 , there is an addition of meaning In the TL headline. The SL word 'angka' refers to a neutral word. It carries the feature of [number, +figure, +digit, -loss, - casualties]. On the other hand, the TL word 'toll' carries the features of [+casualties, +loss]. 'Toll' adds sombre and serious mood as compared to the SL headline. Possible reason for this would be that the translators might want to highlight the severity of the incident which is a strategy to draw attention to the news by arousing readers' sympathy. This serious mood is further emphasized by the use of 'top' which is normally used to indicate the 'highest point'. This amplifies the effect on the message. The SL 'lebih' refers to an action of 'increase'. It also carries the features of [+over, +more than, + increase] while 'top' carries the features of [+exceed, + outrun, + surpass]. The SL word refers to the action of increasing but the TL is more to letting the reader know that the death might exceed the highest peak. The translator may have used the word 'top' as in to emphasize on the extreme increase in the number of casualty. Basically the overall message is retained. In fact, morphologically, syntactically and semantically, both headlines are very similar. The only conspicuous difference is that the TL headline employs more emotionally-attached words such as 'toll' and 'top' which magnifies the effect of the TL headline on the readers.

\subsection{Ambiguous Translation}

In this section, we will present 3 cases of undertranslation. They are presented in tables $9,10,11$ 
Table 9. Headline (Korbanmungkinlebih 10,000)

\begin{tabular}{|c|c|}
\hline SL & Korbanmungkinlebih 10,000 \\
\hline TL & Japan's quake victims increases \\
\hline BT & MangsagempabumiJepunmeningkat \\
\hline $\begin{array}{l}\text { Style of SL } \\
\text { and TL }\end{array}$ & $\begin{array}{l}\text { SL: lebih [Adj] } \\
\text { TL: increases [V] }\end{array}$ \\
\hline $\begin{array}{l}\text { Semantic } \\
\text { features of SL } \\
\text { and TL }\end{array}$ & $\begin{array}{l}\text { SL: lebih }[+ \text { Adj, }+ \text { exceed, }+ \text { more than, }+ \text { over, } \pm \text { rise, } \\
\text { escalate }] \\
\text { TL: increases }[+\mathrm{V},+ \text { rise, },+ \text { grow bigger in number } \\
+ \text { escalate, }- \text { over, - exceed] }\end{array}$ \\
\hline $\begin{array}{l}\text { Effect on } \\
\text { message }\end{array}$ & $\begin{array}{l}\text { The SL and TL headlines differ in style totally } \\
\text { Whereas, for semantic feature, there are some similari } \\
\text { ties. SL term 'lebih' carries ambiguous meaning. Th } \\
\text { first meaning that it carries is exceeding a specific } \\
\text { limit. Another meaning would be gradual increase ir } \\
\text { the number. Due to a two interpretation of the worc } \\
\text { 'lebih', this translation of the text is hence, an Am } \\
\text { biguous Translation. }\end{array}$ \\
\hline
\end{tabular}

The data as shown in Table 12 is an example of an Ambiguous Translation where the style and meaning of the SL and TL texts might or might not have the same meaning due to dual interpretations of the SL term 'lebih'. The SL word 'lebih' carries the semantic feature of [+exceed, + more than, +over, \pm rise, \pm escalate] while the TL word 'increases' carries the semantic features of [+rise, +grow bigger in number, +escalate, - over, - exceed]. The SL term 'lebih' will be an equivalent word for the TL word 'increase' if the SL word functions as a verb which carries the meaning of 'gradual increase'. On the contrary, if the SL term 'lebih' functions as an adjective which carries the meaning of 'more than a particular limit', the translation will be alternated in which the meaning and style are changed. The dual interpretations of the SL text, it is unclear as to whether there is any meaning loss. Thus, this is an Ambiguous Translation.

In headline 9, the word 'korban' in SL is translated into 'victims' in the TL. SL 'korban' carries the features of [+ victims, + death, + injured, + sacrifice $]$ while 'victims' carries the features of [+dead, + injured, - sacrifice, + loss]. 'Korban' signifies specifically to those who are 'dead' but 'victims' can refer to those who are still dead or alive. Here it can be clearly seen that the effect of the word 'korban' is reduced after the translation. It can be said that the translator attempts to reduce the severity of the issue by using a more general statement. Apart from that, there is also addition in the meaning of the TL headline. This is because of the use of the word 'increase' to substitute the word 'lebih' in the SL headline. The word 'lebih' provides specific detail because it is followed by the number of deaths as shown in the SL headline. On the other hand, in the TL headline, the amount is not specified and it is only men- tioned generally that there is an increase in the number of victims. Therefore the impact portrayed by the figure 10,000 reduced is hence reduced.

Although there is loss of information, there is also addition of information in the TL headline. For example, the addition of the phrase 'Japan's quake' is to inform the readers that 'an increase in the number of victims' is actually referring to the recent Japan's earthquake which is of main concern to the society. On the contrary, the SL headline does not indicate the 'amount of deaths' is referring to which incident. The possible reason would be because the translator wanted to catch the attention of readers since this incident has become an issue of concern worldwide. Thus, it seems that the translator is using a strategy different from the author of the SL news to catch the attention of the readers. The change in structure and lexical choice as part of the strategy leads to semantic change. The gist of the SL headline is retained but otherwise, the loss and addition of meaning in the TL headline have brought about quite an explicit change in the meaning of the whole SL text.

Data 10

\section{Table 10. Headline (Angkakematianmungkinlebih 10,000, kata polis)}

\begin{tabular}{|c|c|}
\hline SL & Angkakematianmungkinlebih 10,000 , kata polis \\
\hline TL & Death toll might top 10,000 , says police. \\
\hline BT & Angkakematianmungkinmeningkat 10,000 , kata polis \\
\hline $\begin{array}{l}\text { Style of SL } \\
\text { and TL }\end{array}$ & $\begin{array}{l}\text { SL: lebih [Adj] } \\
\text { TL: top [V] }\end{array}$ \\
\hline $\begin{array}{l}\text { Semantic } \\
\text { features of } \\
\text { SL and TL }\end{array}$ & $\begin{array}{l}\text { SL: lebih }[+ \text { Adj, }+ \text { over, }+ \text { more than, }+ \text { increase }] \\
\text { TL: top }[+\mathrm{V},- \text { Adj, +exceed, + outrun, }+ \text { surpass }]\end{array}$ \\
\hline $\begin{array}{l}\text { Effect on } \\
\text { message }\end{array}$ & $\begin{array}{l}\text { There is difference between the style and semantic } \\
\text { features of SL and TL text. The SL 'lebih' carries } \\
\text { ambiguous meaning. The first meaning that it carries is } \\
\text { 'increasing' and the other meaning would be 'exceeding } \\
\text { a specified limit' whereas the TL 'top' carries the deno- } \\
\text { tation of 'exceeding' and 'surpassing'. Due to a double } \\
\text { interpretation of the SL, this translation can be consid- } \\
\text { ered as Ambiguous Translation. }\end{array}$ \\
\hline
\end{tabular}

The table above indicates that 'lebih' and 'top' undergoes ambiguous translation. There are differences in the styles and semantic features of both SL and TL text. The word 'lebih' is an adjective and it carries the semantic features of [+over, +more than, + increase] while the word 'top' is a verb which carries the semantic features of [+exceed, + outrun, + surpass]. 'Lebih' carries dual meaning whereby it can mean either to exceed a certain limit or the process of increasing. On the contrary, 'top' means to surpass or exceed a certain limit.In headline 10 , there is an 
addition of meaning In the TL headline. The SL word 'angka' refers to a neutral word. It carries the feature of [number, +figure, +digit, -loss, - casualties]. On the other hand, the TL word 'toll' carries the features of [+casualties, +loss]. 'Toll' adds sombre and serious mood as compared to the SL headline. Possible reason for this would be that the translators might want to highlight the severity of the incident which is a strategy to draw attention to the news by arousing readers' sympathy. This serious mood is further emphasized by the use of 'top' which is normally used to indicate the 'highest point'. This amplifies the effect on the message. The SL 'lebih' refers to an action of 'increase'. It also carries the features of [+over, +more than, + increase] while 'top' carries the features of [+exceed, + outrun, + surpass]. The SL word refers to the action of increasing but the TL is more to letting the reader know that the death might exceed the highest peak. The translator may have used the word 'top' as in to emphasize on the extreme increase in the number of casualty. Basically the overall message is retained. In fact, morphologically, syntactically and semantically, both headlines are very similar. The only conspicuous difference is that the TL headline employs more emotionally-attached words such as 'toll' and 'top' which magnifies the effect of the TL headline on the readers.

Data 11

Table 11. Headline (ISA pada yang persenda azan di Youtube)

\begin{tabular}{|c|c|}
\hline SL & ISA pada yangpersendaazan di Youtube \\
\hline TL & Groupcalls for ISA over "mockery" of Azan \\
\hline BT & $\begin{array}{l}\text { Kumpulandipanggiluntuk ISA atas } \\
\text { "ejekan" tentangAzan }\end{array}$ \\
\hline $\begin{array}{l}\text { Style of SL } \\
\text { and TL }\end{array}$ & $\begin{array}{l}\text { SL: yang }[\mathrm{N}] \\
\text { TL: Group calls }[\mathrm{N}-\mathrm{V}]\end{array}$ \\
\hline $\begin{array}{l}\text { Semantic } \\
\text { features of SL } \\
\text { and TL }\end{array}$ & $\begin{array}{l}\text { SL: yang }[+\mathrm{N},+ \text { referential item }] \\
\text { TL: Group }[+\mathrm{N},+ \text { team, } \pm \text { organization }] \\
\text { calls }[+\mathrm{V},+ \text { bring in, + demand, + require, + sum- } \\
\text { mon, + order }]\end{array}$ \\
\hline $\begin{array}{l}\text { Effect on } \\
\text { message }\end{array}$ & $\begin{array}{l}\text { There is difference between the style and semantic } \\
\text { features of SL and TL text. The SL 'yang' can be used } \\
\text { as a referential item to refer to something said earlier } \\
\text { or referring to an implied meaning. However 'Group } \\
\text { calls' carries dual interpretation where it can refer to a } \\
\text { specific group of people who is being called to ISA or } \\
\text { a specific group is asking for ISA to be implemented. } \\
\text { Therefore, there is a process of } \\
\text { Ambiguous Translation. }\end{array}$ \\
\hline
\end{tabular}

There is difference in both the style and the semantic features of the SL text and TL text. The word 'yang' is referred to as a noun $[\mathrm{N}]$ with the semantic features of $[+$ referential item] whereas the translated version is 'group calls' which is more to noun-verb [N-V]. 'Group' carries the semantic features of $[+$ team, \pm organization $]$ while 'calls' carries the semantic features of $[+\mathrm{V},+$ bring in, + demand, + require, + summon, + order]. In the SL text, the referent is being implied by the word 'yang'. It indicates that there is an individual or group who is asking to for the implementation of ISA. However in the TL, the words 'group calls' can imply either to a specific group who is asked to face the implementation of ISA or a specific group is requesting for the implementation of ISA.

In headline 11 , both the SL and TL words carry similar features but the SL word does not carry the tone of sarcasm as the TL word. 'Persenda' carries the features of [+ mockery, + tease, - sarcastic] whereas 'mockery' carries the features of $[+$ sarcastic, + tease, + insult, + contempt $]$. The tone of sarcasm is further emphasized by the use of inverted commas ("mockery"). The TL headline illustrates how sarcastically the translator has viewed the issue. Contradictory to the addition of the meaning in the TL headline [+sarcastic], there is also information loss in TL after the translation. The phrase 'in Youtube' is dropped in the TL headline. Possible reason for the drop of the phrase above might be because the translator wanted to emphasize more on the issue rather than where the issue has taken place. It was also discovered that there is confusion in the meaning of the TL headline 'Group calls'. This is because the phrase 'Group calls' carries dual interpretation. The original meaning of this phrase in SL refers to as 'yang'. Here it is clearly stated that the 'yang' refers to the particular individual or group who is facing the implementation of ISA. However, since there is a dual interpretation for the phrase I TL, it is unclear to which the headline refers to. "Group calls" can be either interpreted as 'a specific group who is asked to face the implementation of ISA' or 'a specific group is asking for the implementation of ISA'. In another word, the TL 'group' can function as an agent (someone that initialize an action) or a patient (the group who is requested).Overall, the TL headline is ambiguous. The intended meaning of the translator is hidden or unclear. Therefore it can be said that the message is not clearly conveyed.

\section{Conclusion}

Through this study, it can be concluded that there is similar procedure or strategy used by the translators to convey the SL (Bahasa Malaysia) message to the TL (English) which is Under Translation, Over Translation, Replacement Translation and Ambiguous Translation. The most common strategy used falls in the Replacement Translation category with 6 occurrences out of the 10 headlines analysed. There are meaning loss and addition in Replacement Translation which results in the change in the message conveyed. An issue can seem more significant or vice versa through the use of words. Thus, the translator plays an important role in maintaining the tone and severity of the intended message. The study has also found some- 
thing noteworthy. As was stated in the methodology, Under Translation supposedly carries lesser contextual meaning from the SL to TL. Interestingly, the findings of this research revealed that TL can carry more contextual meaning while undergoing the process of Under Translation. Generally, most of the translations procedure leads to the loss in the meaning in certain headlines whereas some of the other headlines carry minimal loss in the meaning. This study reveals that cross-cultural influence is important when interpreting and translating two different languages.

\section{References}

[1] Jackson, Howard (1988). Words and their Meaning. London: Longman.UK

[2] Katz, J. J.,\& Fodor, J. A. (1963). The structure of a semantic theory. Language, 39 (2), pp 170- pp 210.

[3] Newmark, P. (1981). Approach to translation. Oxford: Pergamon Press. U.K.

[4] Newmark, P. (1988). A text book of translation. New York: Prentice Hall. U.K. 